\title{
EXTREME SPORT AND RECONSTRUCTION OF IDENTITY IN PERSONS WITH SPINAL CORD INJURIES (SCI)
}

\author{
Suzanna Tangen \\ Katholieke Universiteit of Leuven, Belgium \\ Martin Kudlacek \\ Palacky University of Olomouc, Czech Republic
}

\begin{abstract}
*Corresponding author: KU Leuven, Oude Markt 13, 3000 Leuven, Belgium, Suzanna Tangen, suzannatangen@gmail.com
\end{abstract}

This study aims to explore the meaning extreme sport have to the reconstruction of identity in persons who have sustained spinal cord injuries (SCI). Psychological well- being in persons with spinal cord injury is of crucial matter. Suicide rate in persons with SCI are reported to be three times higher than the average population. This study have a qualitative design with a phenomenological approach, where 4 extreme skiers, recruited from the "WY All Mountain Ski Camp" in Jackson Hole, Wyoming, USA where interviewed. Data triangulation consists of 5 additional sources of data, instructor interview, voluntary assistant interview, field journal, including reflexive research diary, and pilot interview. Data where analyzed by color-coding to identify reoccurring themes. Findings show a consistent loss of identity among participants and the need for recovery was prominent. However, the risk factor specifically in extreme sport cannot say to significantly affect the reconstruction of identity in persons with SCI. Other elements than the risk factor show significance for identity reconstruction, such as social aspects and professional identity. Sports play a highly important role in the process of identity reconstruction, as to regain their normal self, pre injury. Nevertheless, considering all participants of this study obsess an adventurous personality with background in risky activities, and the need to regain the same activities as engaged in pre injury is crucial for the identity reconstruction, one can say extreme sport does affect the identity reconstruction in the participants.

Keywords: Spinal cord injury (SCI), extreme sport, identity, identity reconstruction, risk, thrill seeking, monoskiing

\section{INTRODUCTION}

Psychological well-being in persons with spinal cord injuries is of great consequence. Not only physical readjustments are necessary after having one's life drastically changed, but also social and psychological well-being is affected (Chau et al., 2008; Dijkers, 1997). According to a study from DeVivo, Black, Scott Georgeards \& Stover (1991), suicide is reported to be the largest cause of death in persons with complete paraplegia, and second highest cause of death in persons with quadriplegia. Suicidal rate has fortunately decreased with time, but are reported to still be 3 times higher than the average population
(Cao, Massaro, Krause et al. 2014). People with acquired spinal cord injury are highlighting the need for a reconstruction of identity after having such massive life change (Chau et al., 2008; Dijkers, 1997; Sparkes \& Smith, 2002; Yoshida, 1993).

Extreme sport is being defined by Willig (2008) as: "Recreational physical activity, which carries a risk of serious physical injury and even death". (p. 691). By Bentley, Page \& Macky (2007), extreme sport is labeled as "lifestyle" sport. Numerous of studies have been done on extreme sports related to psychological factors (Brymer, 2005; 2010; Brymer \& Oades, 2009; Brymer \& Shweitzer, 
2012; Willig, 2008), but little done on disability and extreme sports (Carin-Levy \& Jones, 2007; Pasek \& Sckhade, 1996; Taylor \& McGruder, 1996). Previous research explores how extreme sport contributes to identity construction (Brymer, 2010), but not related to specific populations. There are evidence of extreme or adventure sport having great impact on persons with a disabilities self image, selfesteem and quality of life (Carin-Levy \& Jones, 2007; Pasek \& Sckhade, 1996; Taylor \& McGruder, 1996).

It is little focus on extreme or adventure sports in rehabilitation of people with acquired injuries and the need for evidence-based research is prominent. In the literature we can find several qualitative studies done on people with SCI and rebuilding identity and the development of self (Boyce \& FlemingCastaldy, 2012; Sparks \& Smith, 2002; Yoshida, 1993). In Sparkes and Smith`s study participants expressed a need to restore self, following injury (Sparkes \& Smith, 2002). We know physical activity help persons with physical disabilities to improve self-concept and reconstruct identity (Carin-Levy \& Jones, 2007; Lundberg, Taniguchi \& McCormick et al. 2011; Pasek \& Sckhade, 1996; Taylor \& McGruder, 1996). Carin-Levy and Jones (2007) describes how participating in scuba diving made the subjects feel free from their impairment and improved their self-concept. Taylor and McGruder (1996) explain when sea kayaking, participants became more able in the eyes of others, and more equal to able-bodied people. In this article a recreational therapist discuss how people with SCI tend to engage in risk taking activities, after their injury to reconstruct their identity. Further the researcher suggests that rehabilitation processes that do not include activities of novel character might fail to satisfy the client's need for reconstructing their identity. Swann and Bosson (2008) suggest that it's more likely for identity to change within novel environments, where the attention is focused on the self.
However, no research is to be found on highrisk sport and reconstruction of identity in persons with SCI. This is remarkable as the cause of SCI often is related to risks and sensation seeking activities. Automobile crashes $(31,5 \%)$, falls $(25,3 \%)$, motorcycle accidents $(6,8 \%)$ and diving $(4,7 \%)$. Only $4,3 \%$ of the incidents are related to non-risky activities, such as medical/surgical complications (Chen, Tang, Vogel \& DeVido, 2013). Although many incidents are not caused by voluntary risks and related to a risk taking identity, a significant part of them are likely to be. This encourages the presumption that extreme sport activities adapted for people with SCI might contribute to the reconstruction of this person's identity.

3 research questions were raised to thoroughly carry out the aim of the study:

1. What does extreme sport mean to a person with SCI?

2. How does the identity change in a person with SCI, before and after injury, and how is the process of identity reconstruction experienced?

3. In what way did extreme sport play a role in reconstruction of identity for persons with SCI?

\section{METHODS}

As this research aims on exploring the meaning extreme sport have for the reconstruction of identity in persons with SCI, a qualitative method approach is preferable and appropriate to gather data on these lived experiences (Krefting, 1991; Hennink, Hutter \& Bailey, 2010). A non-interventional, exploratory design is chosen.

\section{Participant recruitment}

Four participants are recruited from "WY Adaptive Skiing Experience", an all mountain adapted ski camp provided by Teton Adaptive Sport and Adaptive Adventure in Jackson Hole, Wyoming, USA. The camp had duration 
of 10 days, and where two parted. First part where located in Grand Targhee and second part in Jackson Hole. This camp aims to accommodate persons with physical disabilities with solid intermediate skiing skills, wanting to advance to become all mountain skiers. More specifically off piste, for some also out of bounds, practicing tree crowded areas, deep snow and narrow chutes. The camp has a total of 15 participants whereas 6 meet the inclusion criteria's. Among those 6,4 where chosen by selective sampling due to following causes; One participant got seriously injured, and missed substantial parts of the camp due to hospitalization and research participation could cause additional stress. The last potential participant was distantly engaged in the camp, and did not participate in social activities.

All the participants of this study are engaged in risky activities before and after injury. Motorcycling, free climbing, scuba diving, off road hand cycling and extreme mountaineering in addition to their common interest in monoskiing. Their age vary from 55-60, and age of injury, 23-48. All participants are male, with varied social status and professional occupation.

\section{Data collection}

In depth interviews was conducted on the 4 participants to collect phenomenological data (Martínková \& Parry, 2011; Merleau-Ponty, 1999) surrounding the process of reconstructing identity in relation to extreme sport. The researcher also possesses a spinal cord injury, and attended the camp as a participant equally to the participants of the study. That approach facilitated for the researcher to collect valuable field notes and interview material as the participants as related to the researcher as a peer. Due to this immersed approach, researcher kept a reflexive research diary to prevent bias, reveal preconceived assumptions and maintain as objective and neutral as possible (Krefting,
1991). Concerning data triangulation (Hennink, Hutter \& Bailey, 2010; Krefting, 1991), one instructor and one voluntary assistant where interviewed. First triangulation compared primary interviews with the additional interviews from instructor and voluntary assistant. Second triangulation compared primary interviews with field notes and researchers reflexive diary. All interviews were conducted with use of Skype and audiotaped after completed camp. Duration of interviews varied from $57 \mathrm{~min}$ to $1 \mathrm{~h} 22 \mathrm{~min}$, whereas additional interviews with instructor and voluntary assistant were somewhat shorter.

\section{Analysis}

All interviews were transcribed by the researcher and analyzed with color-coding for reoccurring themes (Ryan \& Bernard, 2003). Themes and subthemes were schematically structured. It is conducted a co-recode procedure on pieces of raw data to enhance dependability as far as it is possible. Final analysis and results are sent to the participants for member check (Krefting, 1991) and returned with positive response from all four.

\section{RESULTS}

Results are presented by reoccurring themes to represent participant's lived experiences, thoughts and feelings concerning their reconstruction of identity in relation to their SCI and extreme sport, according to the research questions, in the most accurate and sincere way possible.

\section{Meaning of extreme sport}

The beginning of the interview started with the researcher asking the participants to talk about their skiing experiences. The importance of skiing quickly occurred. Simply to be physically active, and to regain believes that there are more possibilities in life than a sedentary life style, was expressed with amazement. As the skiing becomes a 
significant part of their life, the value of skiing increases. To a large extent skiing was important and in some cases crucial for the participants of this study.

"To be able to ski, be able to participate in a physical activity at first was fantastic. And then to exhale on it was the most incredible experience, thinking that I had lost the capacity to be involved in anything that was fulfilling, you know, I thought it was gonna be shuffle board and bingo. [...] I don't know how our body can transfer sliding across snow, and turn that into such great pleasure." (Marcus)

About monoskiing: "It gives me a purpose, I think without that, I think life would be a little tough. [...] So, if, if, I think if I haven't done this monoskiing thing I would probably been run down, depressed, I'd probably be in a hospital or I'd be dead probably by now. Nothing to live for." (David)

Together with the element of mastery, the element of equality and freedom was prominent.

About what skiing means to him: "Self satisfaction, you know, like; "Oh man, I think I can really do this." You know. And it gives freedom. Gives you a sense of equality." (David)

\section{Social aspects and therapeutic effect}

The sport the participants are engaged in provides essential social benefits, and are claimed to have a therapeutic effect by most participants of the study.

After finding himself on the same speed level as his off road cycling companions: "So that's great, to sort of be back in that whole social environment again." (Peter)
"It was an incredibly therapeutic experience, besides from just the great pleasure of it." (Marcus)

\section{Risk and thrill seeking}

The risk and thrill seeking aspect of skiing was expressed with diversity. One perspective is affected by the safety considerations one takes on when skiing, another is colored by anxiety and fear (mainly in the learning process), and the third about the urge of finding the fine line between being in control and out of control, when one know a small mistake might cause great injury. Most of the participants do, or have done, other adventurous sports besides skiing. When reflecting upon risk, it's based on all their previous adventure sport experiences. The feeling of mastery is for some more important than the urge for risk.

"It's not going out there and do something crazy, you know, even though it might be crazy for some people, it's not really crazy, because you know your capabilities and you've done all the considerations." (Peter)

To feel like a mountain or a climb is conquered or a line is done with perfection, creates a thrilling experience, and the urge for risk is not the main motivation.

Reflecting over thrill in relation to 5060 hours long climbing trips without sleep, and then later about skiing: "And I've never thought of myself for a second that I was a thrill seeker. Cus I'm not getting a thrill out of it. [...] I don't remember feeling like I was getting a rush or something, but you know, I mean to get to the top of a climb and lie down on the ground you know, I'm like, yeah, you know, yeah, you feel like I have conquered something. [...] I get a thrill out of skiing, yeah, I mean, when everything is clicking, your skiing that lift line, you're bouncing trough that deep snow, it's, there is, I mean, there is, there is something real uh, I guess it releases whatever chemicals there are in you brain or 
whatever cus it is really... Guess you call it thrilling." (George)

However, some of the participants can be considered thrill seekers, and claimed it was a personality characteristic. These participants argued to find risk in all aspects in life, if not in sports. Their worries about getting injured were circled around not being able to ski anymore.

"There is something about being on that line... Being near the edge of control and maybe you vacillate, you are slightly beyond that, and you pull it back in and, and the feeling that, you know that that generate. There's something about being on the edge that is attractive." (Marcus)

When talking about a bad fall in Jackson Hole: "It concerns me that I can do something like that and have an accident that would prevent me from skiing. [...] If you are dead, you don't miss skiing." (Marcus)

\section{Loss of identity}

All the participants experienced some kind of identity loss following their injury. The loss is expressed in different ways, and different identities are affected. Naturally the most significant parts of their identity are exposed to most threat. The areas mostly exposed in the participants of this study are professional identity, social identity, masculine and sexual identity, and athletic identity.

As all the participants are men, the masculine identity, where one supports a family or has a protective role in a relationship, stands out. The aspects in life that is important to that specific person at the time of injury will be crucial to regain for their recovery process. For some, this masculine identity was far more important than e.g. athletic identity.

"From a male perspective that, you know the, you know I think of the men's role in a relationship, you know to, to you would be the physical entity that you could protect upon women, that you could perform sexually, that, these things that you know are perceived as being important when you are 23, and, and when those things are threatened...[...] I felt threatened to, you know, to just as being gimpy and not having women being interested. [...] If a woman would sleep with you then then you know, that somehow supported the fact that you were a man." (Marcus)

"I had bills to pay and I was, you know, I was the, the breadwinner in my family and so, I had get back to work and pay college tuition and, and you know, and still earn for my family." (Peter)

\section{Identity reconstruction}

All the participants expressed a need for a reconstruction of their identity. Those aspects in life that are more prominent had a higher importance of being regained. The way the different participants experienced their identity reconstruction were highly individual.

When his son found a picture book from the recreational department of the hospital he told him: "Dad, you wont believe all the things that you can do, you don't have to give up anything!" So, that was a big change. [...] I didn't spend a long time searching, figuring out, finding my identity again, but I will say that every time I get in a hand cycle or every time I get in my ski, I am, to some extent, trying to regain and relive that life, that athletic life." [...] Doing things on my off road hand cycle is about rediscovering and reaffirming my capability. There is no question about that in my mind." (Peter)

Although a significant period of time has passed since the injury of all participants (1136 years), the identity reconstruction is still ongoing for some and is experienced as being an extensive, long process. 
"I have masters degrees and all this professional life and you feel like you should still count for something. But I think when you are in a wheelchair, you know, you do get written off to an extent. [...] I was seen as this damaged guy, you know. [...] They don't see me as a peer, as somebody who's had a long and professional career. [...] I don't think they would ever seek me, seek my advice." (George)

Extreme sport, risk factor and reconstruction of identity

To answer to the relationship between these elements it is important to clarify extreme sport as being a larger term then the urge for risk and thrill. The risk factor is only a part of extreme sport, although still a significant part. As extreme sport can be important and crucial for the identity reconstruction, the risk factor might not be the essential part influencing this process.

As mentioned before, the urge for risk and thrill is prominent within some participants. Aspects of social life and just simply being active are more important than the thrill seeking and stimulating their urge for risk, concerning their identity reconstruction. The social aspects, meeting people and seeing examples, are aspects that the sport is providing and is expressed with great significance.

"Skiing and hand cycling. Both. I think if I didn't have had these opportunities and just been in these programs and been with these people, seeing these examples, I wouldn't have recovered. Period. I mean, my recovery wouldn't be what it is." (George)

When asked about skiing in relation to his identity reconstruction: "I think that's why I wanna ski so well again so much. It's just, that's my, it is my identity, I mean, not all of it, but strongly it is." (George)
As explained under the section of identity reconstruction, we see that other identities where more exposed for threat. Although this urge for risk is considered a personality characteristic, and an adventurous behavior is a common denominator among all participants, it is likely to believe an adventurous choice of sport is important for their identity reconstruction, but the risk factor specifically have little importance. The other aspects of extreme sport make this activity important in their identity reconstruction process.

\section{DISCUSSION}

I found that persons with SCI have great joy and pleasure in doing extreme sport. For some skiing was even crucial and gave a reason to get up in the morning. Combined with anxiety and sometimes fear there is an urge for risk and thrill and the fine line between being in control and not that is attractive. It was also expressed that the outdoor environment were highly appreciated and the skiing in itself had a therapeutic effect. The social benefits of performing the sport were important to all participants.

These findings are consistent with previous research done on the effect of regular sport and people with SCI (Tomasone, Wesch, Ginis \& Noreau, 2013; Boyce \& Fleming-Castaldy, 2012). The effects are found to be therapeutic and there are comprehensive findings regarding social benefits in previous literature (Chau et al., 2008). In extreme sport research there are findings of athletes being cautious and calculating, working to minimize the risk in the activity (Brymer \& Oades, 2009; Brymer, 2010; Chelsi, Rose \& Leigh, 1993), which is consistent with previous literature. There is literature claiming that extreme sport athletes possess a pathological behavior (Elmes \& Barry, 1999; Monasterio, 2007; Willig, 2008). Findings in this study are contradicting these statements. 
All participants of this study stated a loss of identity related to their SCI. These findings are consistent with previous research (Yoshida, 1993; Boyce \& Fleming-Castaldy, 2012; Dijkers, 1997) whereas it's commonly expressed a loss of athletic and masculine identity (Sparkes \& Smith, 2002), the loss of athletic identity was present, but not prominent in the data of this study. Masculine, social and professional identity had more significance.

The reconstructing process is experienced as a challenging and extensive process, although considered absolutely necessary. It consists of finding a new way to live the life one had before the time of injury. The way the participants went around this challenge is highly individual, and in some cases significantly affected by drugs and painkillers. It seems to be important for the participants to take up again the activities they were engaged in before their injury, if possible. According to Oyserman and Destin (2010), the choice of activity is related to identity, and it will therefore be reasonable for a person in an identity reconstruction process to restart activities they were engaged in prior to their injury. If not the same, then still an activity they can identify with.

When constructing the research questions, in relation to theory and previous research, there were reasons to assume the risk factor in extreme sport would play a significant role in the reconstruction of identity in persons with SCI. According to the data researcher was in possession of, the risk factor seemed to be of little importance, and the research question became almost irrelevant in the context. There were so many other aspects of extreme sport and the reconstruction process overshadowed the element of risk and made it inconsiderable in the big picture.

Nevertheless, among the findings, there was a prominent expression of the need to regain the life one had before the injury, in other words, perform and engage in the same activities as before. As being adventurous is a part of all the participants' personality, and the urge for risk, as a personality characteristic, is especially significant in most, there are reasons to believe extreme skiing becomes a natural choice of sport after their injury. The risk factor in itself does not seem to significantly affect their identity reconstruction, but definitely seems to be of great importance for their general wellbeing, whereas extreme sport is important for their identity reconstruction, in terms of taking up what they did before injury.

There is great lack of literature on this subject, specifying the process of identity reconstruction in persons with disabilities engaging in extreme sport, leaving no opportunities to assess consistency with previous literature on this specific segment.

\section{Limitations}

There is several limitations to this study. The main limitations are simply caused by limited resources of the researcher, such as available time. The low number of participants is an obvious example. As each interview were transcribed and analyzed only by one researcher, this time consuming process limited the sample of the study. In addition it would be preferable to do secondary interviews with all participants. Secondary interviews could provide more accurate and stronger findings. The researchers experience with interviewing is also related to this limitation, as an experienced interviewer would be able to secure more quality data more effectively. Further there are other methodological limitations, caused to limited resources, such as investigator triangulation (Krefting, 1991). An investigator triangulation would provide the perspective of other researchers on the results and findings. These investigators would preferably be from other professional fields, in this case from psychology, recreology and occupational therapy.

\section{Recommendations for future research}


As this research is conducted on participants above the age of 55, it could provide interesting findings to carry out the same study on younger participants.

\section{CONCLUSION}

When investigating the meaning extreme sport have for the reconstruction of identity in persons with SCI, one can conclude that there are various aspects in these participant's life that add or contribute to their identity reconstruction after sustaining a SCI. Being able to work, maintaining a relationship, being physically attractive, being physically active and being functional is more important than experiencing risk, thrill or adventure. However, all participants experienced a loss of identity after their injury, and expressed a need to reconstruct their identity. The reconstruction process was highly individual, and numerous different needs occurred. Nevertheless, common for all participants were the importance of taking up whatever activity one did before the injury concerning their identity reconstruction process. Insignificant to that matter was doing activities distinctively for the risk factor.

However, as for the reconstruction, it is important to start up again with activities that one was engaged with before. All the participants of this study was engaged in adventurous and in some cases extreme sports before their injury. Based on these findings, we can conclude that extreme sport, more specifically, any activity or sport they were engaged in pre injury is important to the participants of this study regarding their identity reconstruction. The risk factor in itself, however, has little or no significance.

\section{REFERENCES}

Bentley, T. A., Page, S. J. \& Macky, K. A (2007). Adventure tourism and adventure sports injury: The New Zealand experience.
Applied Ergonomics, 38, 791-796. DOI:10.1016/j.apergo.2006.10.007

Boyce, K. \& Fleming-Castaldy, R. P. (2012). Active Recreation and Well-Being: The Reconstruction of the Self Identity of Women with Spinal Cord Injury. Occupational Therapy in Mental Health, 28(4), 356-378. DOI: 10.1080/0164212X.2012.708603

Brewer, B. W., Tasiemski, T. (2011). Athletic Identity, Sport Participation, and Psychological Adjustment in People With Spinal Cord Injury. Adapted Physical Activity Quarterly, 28, 233-250.

Brymer, E (2005). Extreme Dude: A Phenomenological Exploration into the Extreme Sport Experience. Unpublished Doctoral Dissertation, University of Wollongong, Wollongong. Retrieved from: http://eprints.qut.edu.au/41068/

Brymer, E. \& Oades, L. G. (2009). Extreme Sport: A Positive Transformation in Courage and Humility. Journal of Humanistic Psychology, 49(1), 114-126. DOI: $10.1177 / 0022167808326199$

Brymer, E. (2010). Risk and extreme sports: A phenomenological perspective. Annals of Leisure Research. 13(1/2), 218-239.

Brymer, E. \& Schweitzer, R. (2012). Extreme sports are good for your health: A phenomenological understanding of fear and anxiety in extreme sport. Journal of Health Psychology. 18(4), 477-487. DOI: $10.1177 / 1359105312446770$

Cao, Y., Massaro, J. F., Krause, J. S., Chen, Y., Devivo, M. J., (2014). Suicide Mortality After Spinal Cord Injury in the United States: Injury Cohorts Analysis. Archives of Physical Medicine and Rehabilitation. 95, 230-235.

Carin-Levy, G \& Jones, D. (2007). Psychosocial aspects of scuba diving for people with physical disabilities: an occupational science perspective. Canadian Journal of Occupational Therapy. 74(1), 614. DOI: $10.2182 /$ cjot.06.07

Celsi, R. L., Rose, R. L., \& Leigh, T. W. (1993). An exploration of High-Risk 
Leisure Consumption through Skydiving. Journal of Consumer Research, 20, 3-23..

Chau, L., Hegedus, L., Praamsma, M., Smith, K., Tsukada, M., Yoshida, K., Renwick, R. (2008). Women Living With a Spinal Cord Injury: Perceptions About Their Changed Bodies. Quality Health Research, 18(2), 209-221. DOI: 10.1177/1049732307312391

Chen Y., Tang Y., Vogel L. C, \& DeVido M. J. (2013). Causes of Spinal Cord Injury. Topics in Spinal Cord Injury Rehabilitation. 19(1), 1-8. DOI: 10.1310/sci1901-1

DeVivo, M. J., Black, K. J., Scott Georgeards, J. \& Stover, S. L. (1991). Suicide Following Spinal Cord Injury. Paraplegia, 29, 620627.

Dijkers, M. (1997). Quality of life after spinal cord injury: A meta analysis of the effects of disablement components. Spinal Cord, 35, 829-840.

Elmes, M. \& Barry, D. (1999). Deliverance, Denial, and the Death Zone: A Study Narcissism and Regression in the May 1996 Climbing Disaster. The Journal of Applied Behavioral Science, 35, 163-187. DOI: 10.1177/0021886399352003

Hennink, M., Hutter, I., \& Bailey, A. (2010). Qualitative Research Methods. SAGE Publications Ltd.

Krefting, L. (1991). Rigor in Qualitative Research: The Assessment of Trustworthiness. The American Journal of Occupational Therapy, 45(3).

Lundberg, N. R., Taniguchi, S., McCormick, B. P., \& Tibbs, C. (2011). Identity Negotiating: Redefining Stigmatized Identities through Adaptive Sports and Recreation Participation among Individuals with a Disability. Journal of Leisure Activities, 43(2), 205-225.

Martínková, I., \& Parry, J. (2011) An Introduction To The Phenomenological Study Of Sport. Sport, Ethics and Philosophy, 5(3), 185-201, DOI: 10.1080/17511321.2011.602571

Merleau-Ponty, M. (1999). Phenomenology of Perception (C. Smith, Trans.). London: Routledge \& Keegan Paul.
Monasterio, E. (2007). The risks of adventure sports/people. The Alpinist. Retrieved from: http://www.alpinist.com/doc/web07f/rberik-monasterio-mountaineering-medicine (1.12.2013).

Oyserman, D. \& Destin, M. (2010). IdentityBased Motivation: Implications for intervention. The Counseling Psychologist, 38(7), 1001-1043. DOI: 10.1177/0011000010374775

Pasek, P. B. \& Schkade, J. K. (1996). Effects of a Skiing Experience on Adolescents With Limb Deficiencies: An Occupational Adaptation Perspective. American Journal of Occupational Therapy. 50(1), 24-31.

Ryan, G. W. \& Bernard, H. R. (2003). Techniques to Identify Themes. Field Methods, 15(1), 85-109. DOI: 10.1177/1525822X02239569

Sale, P., Mazzarella, F., Pagliacci, M. C., Agosti, M., Felzani, G., Franceschini, M. (2012). Predictors of Changes in Sentimental and Sexual Life After Traumatic Spinal Cord Injury. Archives of Physical Medicine and Rehabilitation, 93, 1944-1949. DOI: http://dx.doi.org/10.1016/j.apmr.2012.03.02 3

Sparkes, A. C. \& Smith, B. (2002). Sport, Spinal Cord Injury, Embodied Masculinities, and the Dilemmas of Narrative Identity. Men and Masculinities, 4(3), 258-285. DOI: 10.1177/1097184X02004003003

Swann, W. B., Jr., \& Bosson, J. K. (2008). Identity negotiation: A theory of self and social interaction. In O. P John, R. W. Robins, \& L. A. Pervin (Eds.), Handbook of personality: Theory and research. New York: The Guilford Pres.

Taylor, L. P. S. \& McGruder, J. E. (1996). The Meaning of Sea Kayaking for Persons With Spinal Cord Injuries. American Journal of Occupational Therapy, 50(1), 39-46.

Tomasone, J. R., Wesch, N. N., Martin Ginis, K. A., Noreau, L. (2013). Spinal Cord Injury, Physical Activity and Quality of 
Life: A Systematic Review. Kinesiology Review, 2, 113-129.

Willig, C. (2008). A Phenomenological Investigation of the Experiences of Taking Part in Extreme Sports. Journal of Health Psychology, 13(5), 690-702. DOI:

10.1177/1359105307082459

Yoshida, K., K. (1993). Reshaping of self: a pendular reconstruction of self and identity among adults with traumatic Spinal cord injury. Sociology of Health \& Illness, 15(2), 217-245. 